\title{
AISI M2 Takım Çeliğinin Mikroyapısı ve Mekanik Davranışları Üzerine Derin Kriyojenik İşlemin ve Temperlemenin Etkisi
}

\section{Effect of Deep Cryogenic Treatment and Tempering on Microstructure and Mechanical Behaviors of AISI M2 Tool Steel}

\author{
Abdullah Sert *๑ \\ Eskişehir Osmangazi Üniversitesi, Mühendislik-Mimarlık Fakültesi, Makine Mühendisliği Bölümü, Eskişehir, TÜRKiYE \\ Sorumlu Yazar / Corresponding Author*: asert@ogu.edu.tr

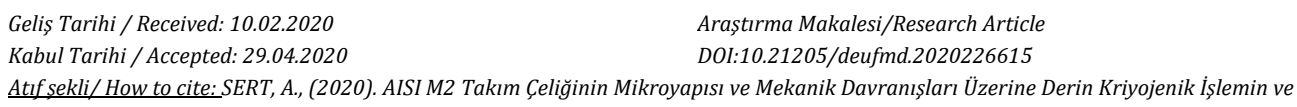

Öz

Bu çalıșmada, AISI M2 takım çeliğinin farklı ısıl işlemler sonucunda mikroyapı ve tribolojik özelliklerindeki değişimi incelenmiştir. Bu amaçla, su verme + temperleme, su verme + derin kriyojenik işlem + temperleme, su verme + temperleme + derin kriyojenik işlem + temperleme şeklinde üç farklı ısıl ișlem prosesi uygulanmıștır. Mikroyapı sonuçlarına göre derin kriyojenik işlem sonrasında mikroyapıdaki karbür tanelerinin boyut ve dağılımlarında iyileşme olduğu belirlenmiştir. Üç farklı ısıl ișlem sonrasında elde edilen sertlik değerlerinde ise belirgin farklılıklara rastlanmamıştır. Ayrıca triboloji testleri sonrasında ise kriyojenik işlemli malzemelerin aşınma oranlarında ve sürtünme katsayılarında düşüş gözlenmiştir. Kriyojenik işlemden hemen önce uygulanan temperleme ișleminin sürtünme katsayısını düșürücü etkisi olduğu belirlenmiștir.

Anahtar Kelimeler: Kriyojenik işlem, Temperleme, AISI M2, Sürtünme

\section{Abstract}

In this study, the change of AISI M2 tool steel in microstructure and tribological properties as a result of different heat treatments were investigated. For this purpose, three different heat treatment processes were applied: quenching + tempering, quenching + deep cryogenic treatment + tempering, quenching + tempering + deep cryogenic treatment + tempering. According to the microstructure results, after deep cryogenic heat treatment, it was determined that the size and distribution of the carbide grains in the structure improved. No significant differences were observed in the hardness values obtained after three different heat treatments. In addition, according to the results of tribology tests, a decrease in wear rates and friction coefficients of cryogenic heat treated materials was observed. It was determined that the tempering process applied just before the cryogenic process reduces the coefficient of friction.

Keywords: Cryogenic treatment, Tempering, AISI M2, Friction 


\section{Giriş}

Yüksek hız çelikleri adından da anlaşılacağı üzere özellikle yüksek proses hızlarında kullanılan kesici takımlarda tercih edilirler. Yüksek sıcaklıklardaki kızıl sertlikleri sayesinde geleneksel takım çeliklerine göre yüksek hızlardaki kesme kabiliyetleri, içerisindeki tungsten, molibden, vanadyum ve kobalt gibi alașım elementlerinin meydana getirdiği karbürler sayesinde daha iyidir [1]. Yüksek hız takım çeliklerinin kullanım alanı, talaşlı imalatın verimliliğinin artırılmasında, özellikle de broşlama ve frezeleme gibi karmaşık hassas aletlerin imalatında önemli bir rol oynar [2]. Çoğu yüksek hızlı çelik takım için, hizmet ömürleri istenildiği gibi değildir ve bunun yanı sıra hizmet ömrünü kısa sürede tamamlamasına bağlı olarak üretimin durmasına ve verimliliğin azalmasına da neden olmaktadır. Bu durum imalat endüstrisini fazlasıyla kötü biçimde etkilemektedir.

Son birkaç on yıldır, özellikle metalik malzemelerin mekanik ve tribolojik özellikleri açısından dayanımlarının arttırılması amacıyla kullanılan konvansiyonel yöntemler yerine günümüzde tercih edilen bir yöntem olan derin kriyojenik işlem prosesi ile aşınma direncinin daha fazla arttığını belirten birçok yayın literatürde yer almaktadır [3-6]. Derin kriyojenik işlem uygulanan malzemelerin mekanik ve mikroyapı özelliklerinde iyileşmeye ve bunun neticesinde ise malzemelerin kullanım ömründe artıș meydana geldiği belirtilmektedir.

Birçok yüksek alaşımlı takım çeliğinde yapılarında yer alan yüksek C nedeniyle su verme sonrasında yapısında kalıntı östenit kalmaktadır [7]. Derin kriyojenik ișlem ile martenzit bitiș sıcaklığının oldukça altındaki sıcaklıklarda malzeme tutularak yapısındaki kalıntı östenitin martenzite dönüşümü mümkün olabilmektedir. Ayrıca yeni ufak boyuttaki karbürlerin oluşması ( $\mathrm{M}_{6} \mathrm{C}$ türünde) ve homojen dağılımı da bu yöntem ile mümkün olabilmektedir. Su verme işlemi esnasında martenzit yapısı meydana gelirken, kristal kafesin boyutlarının değișmesine bağlı olarak karbon atomları dislokasyonların yoğun olduğu bölgelere geçiş yapabilirler. Bu sürecin hemen ardından uygulanan temperleme ile dislokasyonların yoğun olduğu bölgelerde yeni karbürler meydana gelmektedir. Oluşan yeni karbürler sayesinde aşınma direncinde önemli ölçüde iyileşme olduğu bilinmektedir [8]. Takım çeliklerinde en yaygın görülen karbür türleri ve yapı özellikleri Tablo 1'de verilmiştir [9].

M2 yüksek hız takım çeliği üzerine yapılan kriyojenik ișlemli detaylı bir çalışmada [10]; kriyojenik işlemin sıcaklığı $(-80,-120,-160$ ve $\left.196^{\circ} \mathrm{C}\right)$, bu sıcaklığa inilme hızı $(1,2,3,4$ ve 10 $\left.{ }^{\circ} \mathrm{C} / \mathrm{dk}\right)$ ve bu sicaklıkta bekletme süresinin $(1,4$, 12 ve $24 \mathrm{sa}$ ) aşınma direnci üzerine etkileri araştırılmıştır. $\mathrm{Bu}$ çalıșma kapsamında, konvansiyonel isıl işlem ile kriyojenik işlem arasında bir temperleme prosesi yer almamaktadır. Oda sıcaklığından kriyojenik sıcaklığa inilme hızı olarak $2{ }^{\circ} \mathrm{C} / \mathrm{dk}^{\prime} l \mathrm{lk}$ parametrenin tribolojik açıdan en ideal durum olduğu belirlenmiştir. Buna ilave olarak kriyojenik sıcaklığın daha düşük sıcaklıklarda yapılması ve bu sıcaklıklarda bekletme süresinin artması ile malzemelerdeki tribolojik özellikler iyileșmektedir. Farklı östenitleme sıcaklığı (980, $\left.1080{ }^{\circ} \mathrm{C}\right)$, kriyojenik sıcaklığa inilme hızı $(1,5$ $\left.{ }^{\circ} \mathrm{C} / \mathrm{dk}\right)$, kriyojenik sıcaklıkta bekletme süresi $(1$, 5 sa), kriyojenik sıcaklıktan oda sıcaklığına ısıtma hızı (yavaş, hızlı) ve temperleme sıcaklığı $\left(430,500^{\circ} \mathrm{C}\right)$ parametrelerinin derin kriyojenik işlem üzerindeki etkisini araştıran bir çalışmada [11], AISI D2 takım çeliği üzerinde mekanik özellikleri etkileyen en etkin parametrelerin östenitleme ve temperleme sicaklıkları olduğu belirlenmiştir. Yüksek östenitleme ve düşük temperleme sıcaklıklarının sertlik ve aşınma özellikleri üzerinde iyileştirici etki oluşturduğu bildirilmiștir. Yakın zamandaki bir araștırmada ise [12], yüksek karbonlu çeliklerin östenitleme ve su verme isıl ișleminden sonra temperlenmiș ve temperlenmemiş numuneleri inceleyerek kalıntı östenit üzerindeki etkisi araștırılmıștır. Temperlenmiş numunlerde nano boyuttaki karbürlerin oluștuğunu ve kalıntı östenitin daha kararlı bir yapıya geldiği belirlenmiștir.

Derin kriyojenik işlem üzerine yapılan literatürdeki çalıșmalarda temperleme ișleminin araştırılmasından daha çok kriyojenik işlem parametrelerinin malzemeler üzerindeki etkileri araștırılmıştır. Literatürdeki kriyojenik işlemli çalışmaların geneline bakıldığında, su verme ısıl ișleminin hemen ardından derin kriyojenik ișlem uygulanmaktadır. Yapılan bu çalışma kapsamında M2 takım çeliğine su verme ısıl işleminden sonra temperleme uygulanmış ve uygulanmamıș durumlarının derin kriyojenik ișlem ile birlikte mikroyapı ve tribolojik özelliklere etkisi incelenmiştir. 
DEÜ FMD 22(66), 801-811, 2020

Tablo 1. Takım çeliklerinde bulunan karbür mikroyapıları [9].

\begin{tabular}{|c|c|c|c|}
\hline Karbür Türleri & $\begin{array}{c}\text { Karbürü Oluşturan } \\
\text { Elementler }\end{array}$ & Kristal Yapı & Geometri \\
\hline MC & V (genelde), W, Mo, Cr & Yüzey merkezli kübik & Kümeleşmiş \\
\hline $\mathrm{M}_{2} \mathrm{C}$ & Mo, W (genelde), V, Cr & Hekzagonal & İğnemsi \\
\hline $\mathrm{M}_{6} \mathrm{C}$ & Mo, W (genelde), V & Yüzey merkezli kübik & Lamelli \\
\hline $\mathrm{M}_{7} \mathrm{C}_{3}$ & $\mathrm{Cr}$ (genelde), V, Mo, Fe & Hekzagonal & Lamelli \\
\hline $\mathrm{M}_{23} \mathrm{C}_{6}$ & $\mathrm{Cr}$ (genelde), V, Mo, Fe & Kübik (kompleks) & Lamelli \\
\hline
\end{tabular}

\section{Materyal ve Metot}

Deneysel çalışmalarda kullanılan numunelerin ağırlıkça kimyasal bileşimi; \% 0,9 C, \% 0,37 Si, \% 0,31 Mn, \% 0,027 P, \% 0,001 S, \% 3,91 Cr, \% 4,93 Mo, \% 0,15 Cu, \% 1,82 V, \% 6,16 W, \%81,422 Fe'dir. $25 \mathrm{~mm}$ çapında ve $10 \mathrm{~mm}$ yüksekliğinde bar şeklindeki AISI M2 takım çeliği kullanılmıştır. Numunelere uygulanan üç farklı ısıl işlem süreci (Şekil 1) ve numune kodları Tablo 2'de verilmiştir. Östenitleme isıl işlemi $1200{ }^{\circ} \mathrm{C}$ 'de 1 saat sürede gerçekleștirilmiștir ve ardından yağ ortamında su verilmiștir. Uygulanan temperleme işlemleri ise $30 \mathrm{dk}$ süre ile gerçekleştirilmiştir. Kriyojenik işlem sürecinde ise oda sıcaklığından $2^{\circ} \mathrm{C} / \mathrm{dk}$ hız ile kontrollü soğutma ünitesi kullanılarak $-196^{\circ} \mathrm{C}$ sıcaklığa inilip 24 saat bekletildikten sonra yine $2{ }^{\circ} \mathrm{C} / \mathrm{dk}$ hız ile oda sıcaklığına ısıtılmıştır.

Tablo 2. Isıl işlem prosesleri.

\begin{tabular}{|c|c|}
\hline Numune Kodu & Isıl İşlem Detayı \\
\hline HT1 & $\begin{array}{l}\text { Östenitleme }\left(1200{ }^{\circ} \mathrm{C}\right)+\text { yağda } \\
\text { suverme + Temperleme }\left(550^{\circ} \mathrm{C}\right)\end{array}$ \\
\hline HT2 & $\begin{array}{l}\text { Östenitleme }\left(1200 \quad{ }^{\circ} \mathrm{C}\right)+\text { yağda } \\
\text { suverme + Derin kriyojenik işlem }(- \\
\left.196^{\circ} \mathrm{C}\right)+ \text { Temperleme }\left(250^{\circ} \mathrm{C}\right)\end{array}$ \\
\hline HT3 & $\begin{array}{l}\text { Östenitleme }\left(1200{ }^{\circ} \mathrm{C}\right)+\text { yağda } \\
\text { suverme }+ \text { Temperleme }\left(550^{\circ} \mathrm{C}\right)+ \\
\text { Derin kriyojenik işlem }\left(-196^{\circ} \mathrm{C}\right)+ \\
\text { Temperleme }\left(250^{\circ} \mathrm{C}\right)\end{array}$ \\
\hline
\end{tabular}

Mikrosertlik testleri 200 grf kullanılarak FV-700 Future Tech sertlik cihazında gerçekleştirilmiştir. Sertlik ölçümleri 3'er kez tekrar edilerek ortalaması ele alınmıștır. Mikroyapı analizleri için numuneler parlatılıp pikral dağlayıcısı ile dağlandıktan sonra taramalı elekron mikroskobu (SEM, ZEISS VP50, $20 \mathrm{kV}$ ) ile incelenmiștir. SEM görüntüleri üzerinde yapılan kimyasal analizler için enerji dağılımlı spektroskopi (EDS) kullanılmıştır. Mikroyapı içerisinde yer alan karbürlerin boyut ve miktar analizleri için ImageJ yazılımı kullanımıștır. Faz analizleri için X-ışınları kırınımı (XRD, Bruker D8 Advance, $\mathrm{CuK} \alpha$ radiation) cihazı $30^{\circ}-90^{\circ} 2 \theta$ tarama aralığında kullanılmıştır.
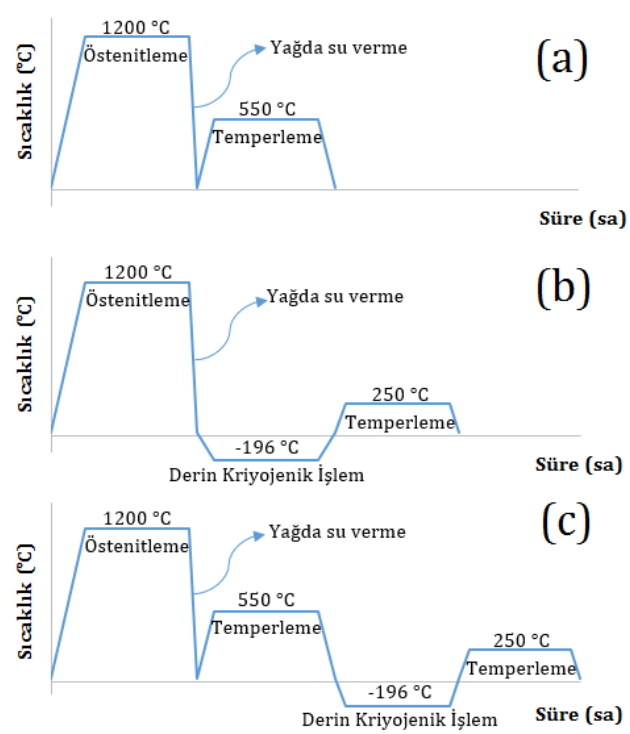

Şekil 1. Numunelere uygulanan isıl işlem süreçleri (a) HT1, (b) HT2, (c) HT3

Triboloji testleri ball-on-disk geometrisinde kuru sürtünme şartlarında CSM Tribometer cihazında $1 \mathrm{~N}$ yük altında ve $5 \mathrm{~cm} / \mathrm{s}$ hızında gerçekleştirilmiştir. Testlerde aşındırma yarıçapı $2 \mathrm{~mm}$ ve toplam aşındırma miktarı 
10000 tur olarak ele alınmıștır. Așınma esnasında sürtünme katsayısı değerleri bir yazılım tarafından kaydedilmiştir. Aşınma oranları, aşınan kanalların profillerinin Mitutoyo SJ-400 cihazı kullanılarak tespit edilmesi ile belirlenmiştir.

\section{Bulgular}

Şekil 2'de ısıl işlem uygulanmış numunelere ait SEM mikroyapıları görülmektedir. Yapılan üc farklı ısı işlem sonucunda mikroyapıda meydana gelen farklı boyutlardaki karbürler martenzitik yapı üzerinde görülebilmektedir. Şekil 2a'da geleneksel su verme yöntemi ile elde edilen HT1 numunesi yer almaktadır. Isıl işlemler sonrasında meydana gelen irili ufaklı açık gri renkte karbürler görülebilmektedir. Özellikle tane sınırlarında karbürlerin kümeleștiği ve daha büyük boyutlarda olduğu görülmektedir. Sekil üzerinde bu bölgeler (iri boyuttaki karbürler) birincil karbürler olarak gösterilmiștir. Literatürde de özellikle yüksek alaşımlı takım çeliklerinde geleneksel su verme ısıl ișleminden sonra büyük boyutlarda karbürlerin oluștuğu belirtilmiștir ve bu karbürlere birincil karbür adı verilmektedir [13]. Geleneksel ısıl ișlem sonucunda yüksek alașımlı takım çeliklerinde bir miktar kalıntı östenit kalmaktadır. Bu kalıntı östenit miktarını azaltmak ve yeni ufak boyutta ikincil karbürler oluşturmak maksadı ile kriyojenik işlem uygulanmaktadır [13]. Geleneksel takım çeliklerinin üretimi esnasında yarı kararlı $\mathrm{M}_{2} \mathrm{C}$ karbürleri daha kararlı yapıdaki karbür formlarına dönüşebilmektedir. Literatürde $\mathrm{M}_{2} \mathrm{C}$ türündeki karbürlerin daha kararlı duruma geçtikleri mekanizma " $\mathrm{M}_{2} \mathrm{C}+$ matris $\rightarrow \mathrm{M}_{6} \mathrm{C}+$ MC" șeklinde bahsedilmektedir [14,15]. Temperleme işlemi sonrasında birincil ve ötektik karbürlerin difüzyon yoluyla kimyasal bileşimi değişir. Yüksek sıcaklıkta belirli bir süre bekletildiğinde serbest yüzey enerjisini azaltarak daha kararlı hale gelebilmek için bütün karbür türleri kümeleșebilir ve küreselleșebilir [16]. Özellikle Şekil 2b-c'de HT2 ve HT3 numunelerinde homojen dağılımlı ufak ve küresel karbürler yer almaktadır. HT1 numunesinde ise geleneksel su verme işleminden sonra karbürlerin kümeleștiği açıkça görülmektedir.

Peng ve diğerleri [17], S390 HSS malzemesine farklı sıcaklıklarda östenitleme ve temperleme işlemi uygulamışlardır. Yapılan ısıl işlemler sonrasında yapıda sadece ufak $\mathrm{MC}$ ve $\mathrm{M}_{6} \mathrm{C}$ karbürlerinin bulunduğunu ve bu karbürlerin yarı kararlı olduğunu ve östenitleme işleminde dahi yapı içerisinde çözünebileceğini belirtmişlerdir. Bunun sonucunda ise bu karbürlerin boyutlarının daha da küçülebileceğini büyük boyuttaki karbürler ise yüzey enerjisi küçük karbürlere nazaran daha az çözündügünü ve bunun sonucunda yapıda MC karbürleri (Vanadyum'ca zengin) büyük halde görüldüğünü bildirmişlerdir. Bunun yanı sıra temperleme işlemi sonrasında küresel ve birbirinden ayrık durumda karbürlerin oluştuğu belirtilmiştir. Ayrıca su verme sonrasında yapılan temperleme neticesinde ise yapıda tempersiz numuneye göre daha fazla oranda MC (VC - Vanadyum karbür) olduğunu belirlemişlerdir.

Șekil 3'te SEM analizleri sonrasında üç farklı ısıl işlem ile elde edilen mikroyapılardaki karbür boyutlarının mikroyapıdaki hacimsel (mikroyapı da bulunan tüm karbürlerin, birbirlerine göre hacimsel oranı) oranları verilmiștir. Yapılan bu analizler mikroyapıların en az üç farklı bölgesinden alınan görüntülerden yapılmıștır ve çıkan sonuçların ortalaması ile grafik çizilmiştir. Literatürde karbür boyutları üç grupta incelenmiștir; boyutları $1 \mu$ m'den ufak olan küçük ikincil karbürler, boyutları 1 ile $5 \mu \mathrm{m}$ arasında olan büyük ikincil karbürler ve boyutları $5 \mu$ m'den büyük olan birincil karbürlerdir [18]. Şekil 3 incelendiğinde, derin kriyojenik işlem uygulanan HT2 ve HT3 numunelerinde, HT1 numunesine göre 1 mikrondan küçük karbür oranı daha fazladır. HT1 numunesinde ise $1-5 \mu \mathrm{m}$ arası ve $5 \mu \mathrm{m}$ 'den büyük karbür hacimsel oranı HT2 ve HT3 numunelerine göre daha fazladır. Derin kriyojenik ișlem neticesinde küçük ikincil karbürler meydana geldiği analizler sonucunda ortaya çlkmaktadır. Literatürde de yer alan benzer bir çalışmada, yüksek hız çeliğine farklı kriyojenik ișlemler uygulanmıș ve mikroyapıda kriyojenik işlemden sonra küçük ikincil karbürlerin ortaya çıktığını belirtmişlerdir [19]. $1 \mu$ m'den ufak karbür oranları incelendiğinde, en fazla oran HT2 numunesinde görülmektedir. HT3 numunesi kriyojenik işlemden önce temperlendiği için oluşan ikincil karbür oranı $\% 46,8$ 'dir ve HT2'nin ikincil karbür oranı \%51,4'ten daha azdır. Derin kriyojenik ișlem uygulanmayan HT1 numunesinde ise bu oranın en az olduğu görülmektedir. Bunların yanı sıra HT1, HT2 ve HT3 numunelerine ait ortalama 
karbür boyutları sırasıyla 1,85, 1,29 ve 1,34 $\mu$ m'dir.. 1 mikrondan küçük karbür oranları ile uyumlu olarak HT2 nin ortalama karbür boyutunun en küçük, sonra sırasıyla HT3 ve HT1 olduğu belirlenmiştir.

Şekil 4'te numunelere uygulanan isıl işlemlerden sonra yapılan EDS analizleri verilmiștir. Karbürler üzerinden alınan EDS analizleri sonucunda, Şekil 4a'da yapılan analizde $W$ ve Mo elementlerine ait \% ağırlıkça oranlar sırasıyla 36,7 ve $25,78^{\prime}$ dir. Şekil $4 \mathrm{~b}-\mathrm{c}$ de yapılan analizlerde de benzer oranlar elde edilmiştir.

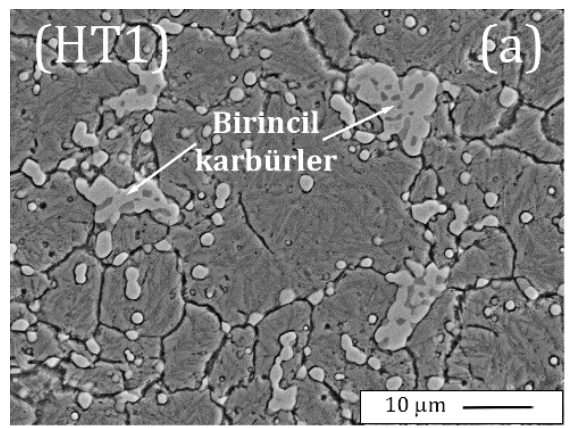

Şekil 4d'de yapılan çizgisel EDS analizinde V elementine ait \% 57,93 ağırlıkça orana sahiptir. Yapılan EDS analizleri sonucunda elde edilen kimyasal birleşimler ile Versaci'nin [20] çalışmasındaki AISI M2 çeliğine yaptığı ısıl işlemler sonucunda elde ettiği kimyasal bileșim oranları benzerlik göstermektedir. Bu oranlar neticesinde Şekil 3abc'de incelenen karbürlerin $\mathrm{M}_{6} \mathrm{C}$, Şekil 3d'de analizi yapılan koyu gri renkteki karbürün ise $\mathrm{MC}$ yapıdaki bir karbür olduğu söylenebilir. $\mathrm{M}_{6} \mathrm{C}$ karbür yapıları $\mathrm{A}_{3} \mathrm{~B}_{3} \mathrm{C}$ ve $\mathrm{A}_{4} \mathrm{~B}_{2} \mathrm{C}$ formlarında olabildiği gibi $\mathrm{A}(\mathrm{Fe}, \mathrm{Cr})$ ve $\mathrm{B}(\mathrm{W}$, Mo) elementlerinden oluşur.
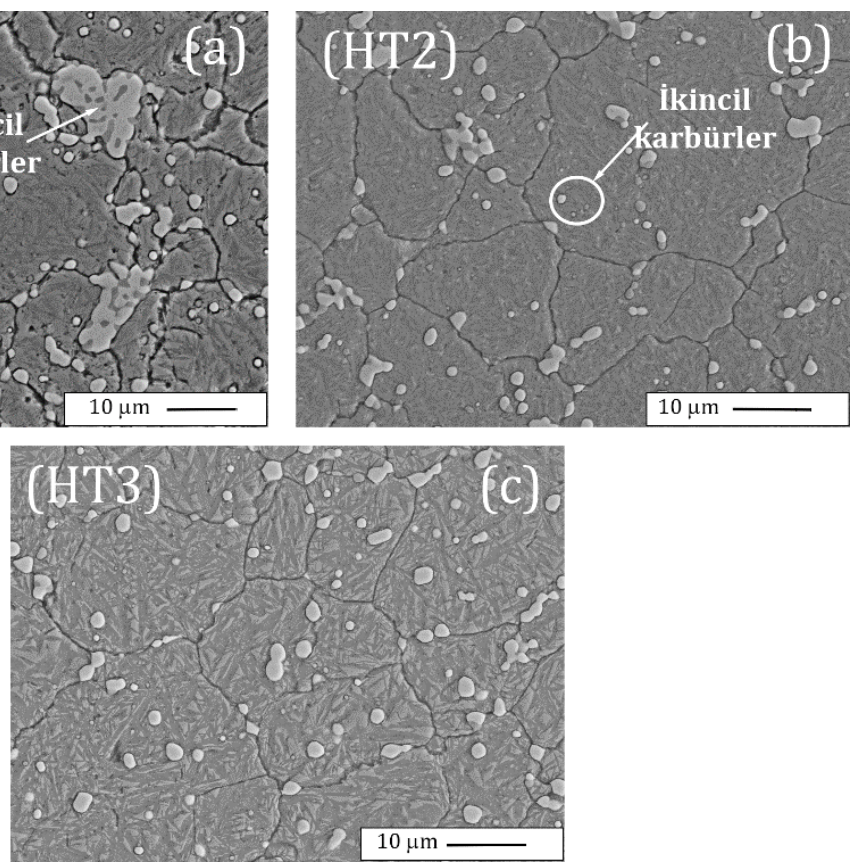

Şekil 2. Farklı ısıl işlemli numunelere ait mikroyapı görüntüleri

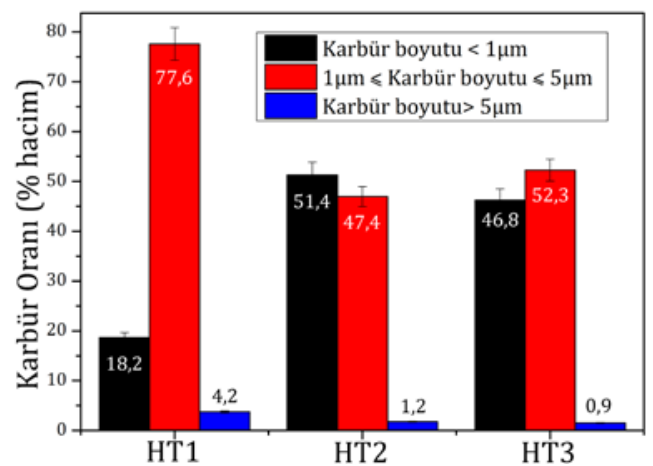

Şekil 3. Farklı ısıl işlemler sonrasında farklı boyutlarda oluşan karbürlerin hacimsel oranları
Farklı ısıl işlemler sonrasında numunelere ait elde edilen XRD spekturumları Şekil 5'te görülmektedir. Sadece $\mathrm{M}_{6} \mathrm{C}, \mathrm{MC}$, martenzit ve kalıntı östenit fazları belirlenmiștir. Su verme işleminin hemen ardından derin kriyojenik ișlem uygulanması ile HT2 nolu numunede kalıntı östenit fazına ait pik $\left(49^{\circ}-50^{\circ}\right)$ şiddetinin diğer numunelere göre çok düşük olduğu görülmektedir. Literatürde de yüksek alaşımlı ve karbonlu takım çeliklerine uygulanan kriyojenik işlem ile su verme prosesinin hemen ardından yapıda bulunan kalıntı östenitin martenzite dönüştüğü belirtilmiştir [21]. HT3 nolu numunede derin kriyojenik işlem uygulanmasına rağmen kalıntı östenite pik şiddetlerinin HT2'ye ait pik şiddetlerinden fazla 
DEÜ FMD 22(66), 801-811, 2020

olması, derin kriyojenik ișlem öncesinde $550{ }^{\circ} \mathrm{C}$ temperleme işleminin uygulanması ile kalıntı östenitin daha kararlı hale geldiği [12] ve böylece derin kriyojenik işlemi uygulansa dahi yapının tamamının martenzite dönüşmediği söylenebilir. Yüksek hız çeliklerinde geleneksel su verme işleminden sonra temperleme işlemi yaklaşık olarak $550-560{ }^{\circ} \mathrm{C}$ yapılır. Bununla beraber temperleme işlemi genellikle kalıntı östenitin kalmaması amacıyla üç kez tekrar edilir [8,22]. $\mathrm{Bu}$ çalıșma kapsamında su vermeden sonraki temperleme prosesi isıl ișlem maliyetini azaltmak amaciyla 1 kez gerçekleştirilmiștir. Kriyojenik ișlemden sonra uygulanan $250{ }^{\circ} \mathrm{C}$ temperleme işlemi ise kriyojenik işlemden kaynaklı kalıntı gerilmelerin giderilmesi amacıyla yapılmıștır.

500-550 ${ }^{\circ} \mathrm{C}$ aralığında temperleme işlemi esnasında yüksek karbon içeriğine sahip kalıntı östenitten yeni karbürler meydana gelir ve martenzit dönüşüm sıcaklığı (Ms) yükselir. Sonuç olarak, martenzit dönüşümü temperleme sonrası soğutma esnasında da gerçekleşebilir [8]. Bu durumda konvensiyonel su verme işleminin ardından temperleme prosesinin yapılması ve ardından derin kriyojenik ișlem uygulanması durumunda kararlı karbür yapılarının oluşması muhtemeldir. Godec ve diğerleri [1], AISI M42 yüksek hız çeliğinde karbür oluşumunu $\mathrm{M}_{2} \mathrm{C}+$ matris $\rightarrow \mathrm{M}_{6} \mathrm{C}+\mathrm{MC}+$ matris formunda gerçekleştiğinden bahsetmişlerdir. $\mathrm{M}_{2} \mathrm{C}$ karbürünün $\mathrm{V}$ elementi açısından MC karbürüne göre daha zengin olduğunu belirtmişler ve buna göre karbür oluşum mekanizması sonucunda MC karbürünün $\mathrm{V}$ oranınca zengin olacağını açıklamışlardır. Ayrıca bu duruma bağlı olarak MC karbürlerinin çoğunlukla $\mathrm{M}_{6} \mathrm{C}$ karbürlerinin tane sınırlarında görüldüğünü de belirtmişlerdir. $\mathrm{Bu}$ durum Şekil 4d'de çizgisel EDS analizinin olduğu karbür tanesinde görülebilir. Açlk gri minik karbür tanelerinin kümeleștiği bölgede koyu gri renkte MC karbürüne rastlanmıştır.
Sekil 6'da numunelere ait makrosertlik değerleri verilmiștir. Isıl işlemsiz, HT1, HT2 ve HT3 numunelerine ait sertlik değerleri sırası ile 27,1, $64,4,64,5$ ve 66,2 HRC'dir. Isıl işlemler sonrasinda HT1, HT2 ve HT3 arasında sertlik açısından kriyojenik işlemli numunelerde bir artış olmasına rağmen belirgin bir farklılık görülmemektedir. Literatürde de benzer olarak farklı şekillerde kriyojenik işlem uygulanmış takım çeliklerinde belirgin bir farklılık görülmemektedir. Sertlikte bariz farklılığın olmamasına rağmen așınma özellikleri açısından belirgin farklılıklar olduğu belirtilmiștir [21,23].

AISI M2 yüksek hız çeliği özellikle kesici takım olarak kullanılması durumunda aşınma en önemli hata durumudur. Bu amaçla uygulanan ısıl işlemli numuneler aşınma deneylerine tabi tutulmuşlardır. Şekil 7'de 3 farklı ısıl işlemli numuneye ait atmosferik şartlarda gerçekleştirilen aşınma deneylerinden elde edilen sürtünme katsayısı grafiği görülmektedir. Geleneksel isıl işlemli HT1 numunesine ait sürtünme katsayısı değerinin derin kriyojenik işlem uygulanmıș numunelere göre daha yüksek olduğu görülmektedir. Derin kriyojenik işlem uygulanmış numunelerde ise eğriler birbirine oldukça yakın değerlerdedir. Bununla birlikte HT3 nolu numunenin daha düșük sürtünme katsayısına sahip olduğu görülmektedir. Așınma testleri esnasında aşındırıcı bilye ile numuneler arasındaki sürtünme katsayısı ilk etapta yükselis göstermektedir. Daha sonra bir geçiş aşamasından geçer ve yavaş yavaş kararlı bir duruma dönüşür. Bu geçiş aşamasında, sürtünme katsayısında bir düşüş gözlenir. Sürtünme katsayısındaki düşme ise karşılıklı temas eden yüzeylerin kayma esnasında yüzeyleri daha pürüzsüz hale getirmesi olduğu söylenebilir. Bu durumun ardından sürtünme katsayısında aşınma partiküllerinin kayma yüzeyleri arasına girmesi ile yine bir artıș gözlenir. Yukarıda anlatılan olgu, detaylı olarak Grairia ve diğerleri tarafından ele alınmıștır [24]. 
DEÜ FMD 22(66), 801-811, 2020

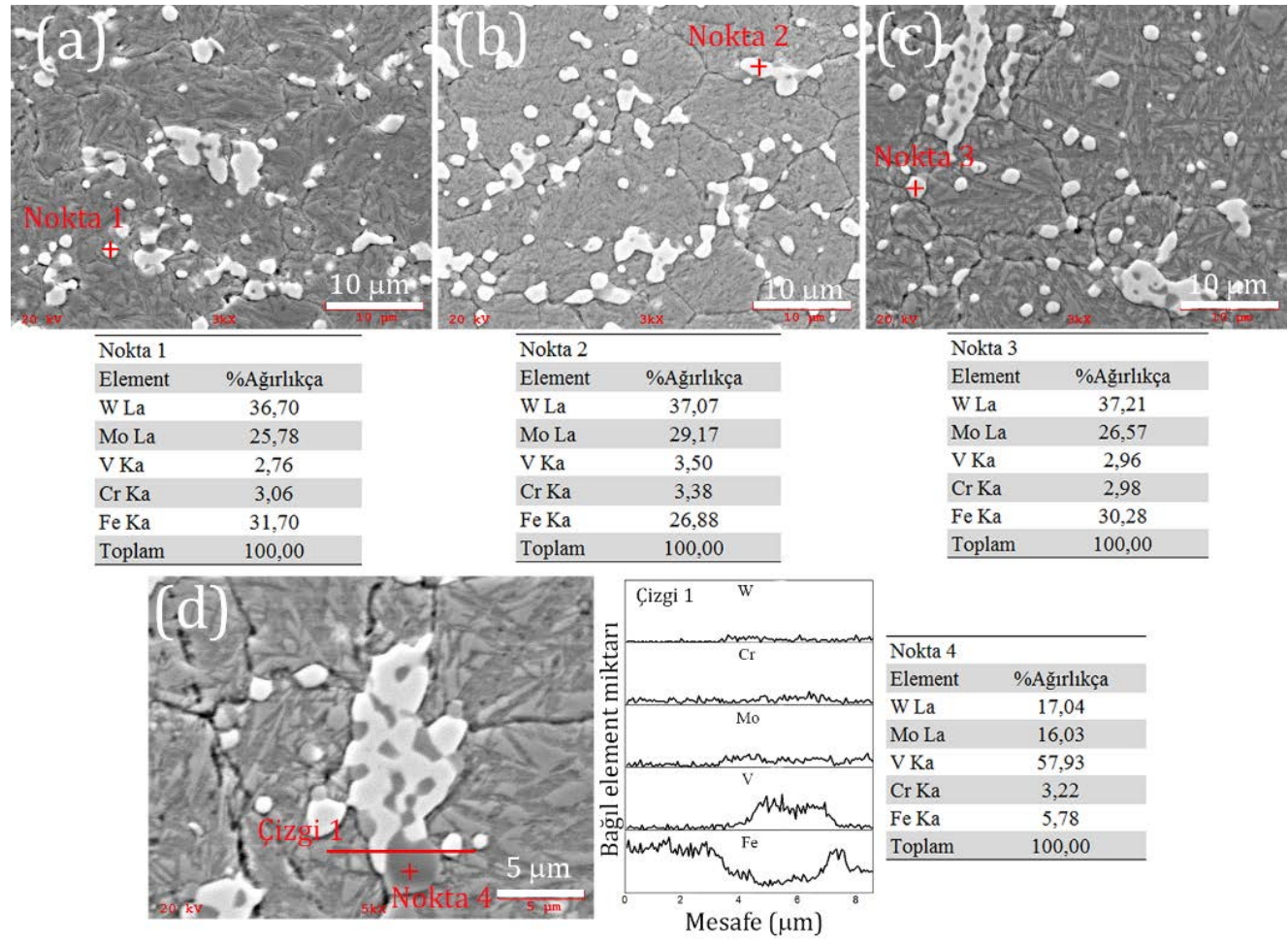

Şekil 4. Farklı ısıl işlemler sonrasında mikroyapıda meydana gelen karbürler (a) HT1, (b) HT2, (c) HT3, (d) HT3 detaylı

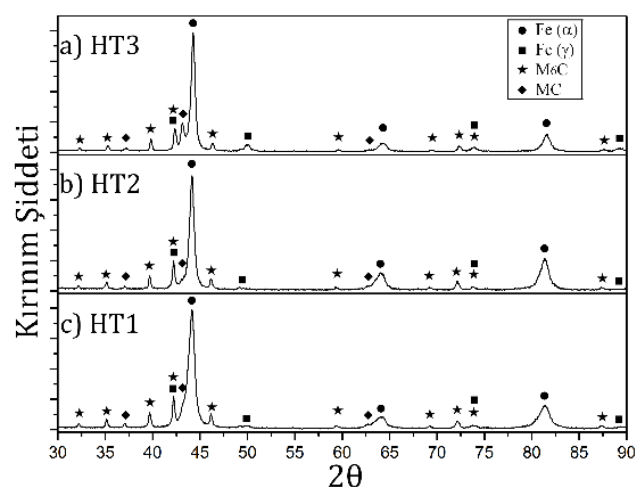

Şekil 5. Farklı ısıl işlemli numunelere ait XRD analizleri

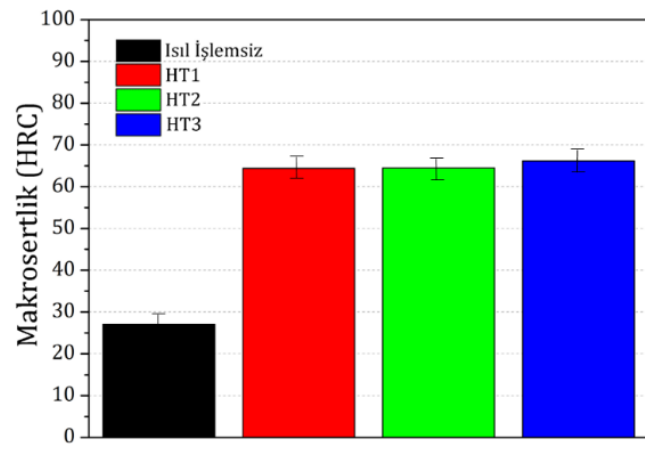

Sekil 6. Farklı ısıl ișlemli numunelere ait mikrosertlik değerleri 


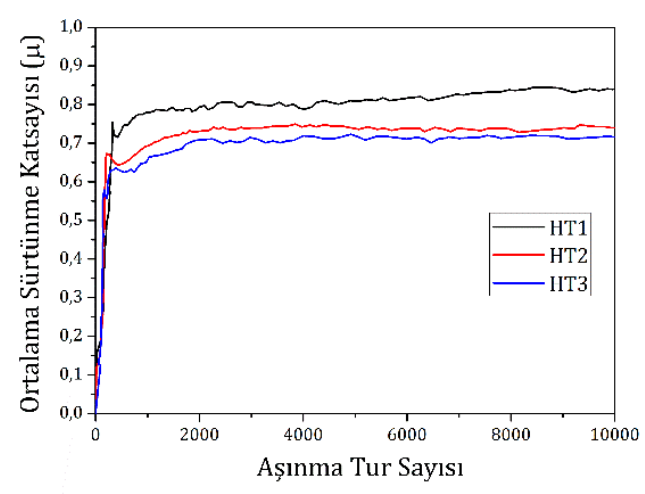

Şekil 7. Isıl işlemli numunelere ait aşınma tur sayısına bağlı ortalama sürtünme katsayısı değerinin değişimi

HT2 ve HT3 numunelerinde daha düşük sürtünme katsayısının oluşma sebebi ise, derin kriyojenik işlem neticesinde yapıda meydana gelen ikincil karbürlerin yapıya çok iyi tutunarak yüzeyin hem az aşınmasına hemde karşıt aşındırıcı malzemenin altlık malzeme üzerinde kayarak adhezif ve abrazif etkiyi azalttığı yapılan önceki çalışmalarda da belirtilmiştir [25]. En düşük sürtünme katsayısının HT3 numunesinde olması durumu ise, hem derin kriyojenik işlem sonrasında yapısında ufak ikincil karbürler oluşmasıdır hemde Zhang ve diğerlerinin [26] belirttiği üzere kalıntı östenitin yağlayıcı özelliğinden kaynaklıdır. HT3 numunesinde XRD sonuçlarında kalıntı östenit fazının HT2 numunesine göre fazla olduğu belirlenmiștir. HT3 numunesindeki kalıntı östenitin ise temperleme işleminden sonra kararlı bir yapıya sahip olduğu daha önceki bulgularda belirtilmiştir.

HT1, HT2, HT3 numunelerine ait aşınma kanalı görüntüleri Șekil 8'de verilmiștir. Șekil 8abc' deki görüntülerde aşınma doğrultusu boyunca aşınma kanalları ve bunun yanısıra aşınmanın adhezif ve abrazif olduğu görülmektedir. HT1, HT2 ve HT3 numunelerindeki aşınma morfolojileri birbirine benzemektedir. HT1 numunesinde delaminasyon miktarının biraz daha fazla olduğu görülebilmektedir. Yapı içerisindeki minik karbürlerin HT2 ve HT3 numunelerindeki gibi fazla belirgin olmadığı, karbürlerin üzerine matrisin delamine olduğu görülebilmektedir. HT2 ve HT3 de ise kayma esnasında derin kriyojenik işlem sonucunda yapıda daha kararlı halde bulunan karbürlerin matrisin kayma esnasında plastik deformasyona uğramasını önlediği söylenebilir. Zhang ve diğerleri [26], kümeleşmiş MC karbürlerin, $\mathrm{M}_{2} \mathrm{C}$ karbürlere kıyasla mikroyapıya güçlü bir şekilde sabitlendiğini ve ağır yükler tarafından kolayca ezilmediğini belirtmişlerdir. Yüksek hız çeliklerindeki VC karbürler yüksek serlik değerlerinden dolayı $\mathrm{M}_{2} \mathrm{C}$ ve $\mathrm{M}_{6} \mathrm{C}$ tipindeki karbürlere kıyasla mükemmel aşınma özelliklerine sahiptir.

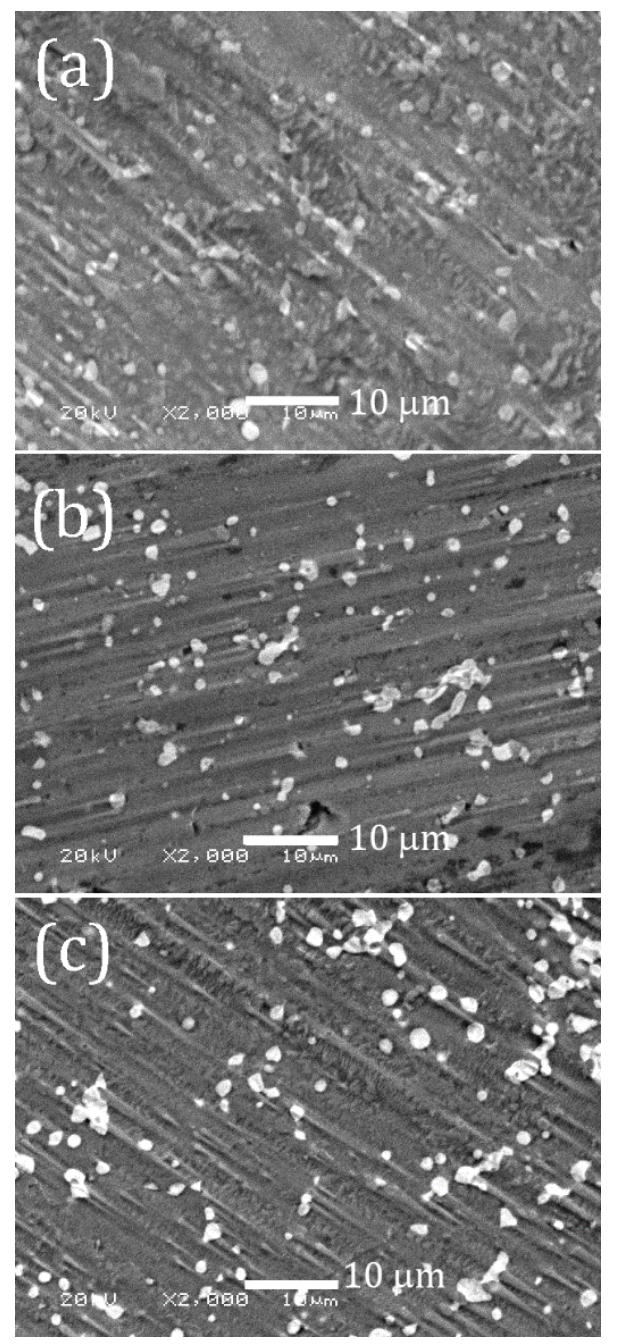

Şekil 8. Isıl işlemli numunelere ait aşınma kanalı görüntüleri (a) HT1, (b) HT2, (c) HT3 
DEÜ FMD 22(66), 801-811, 2020
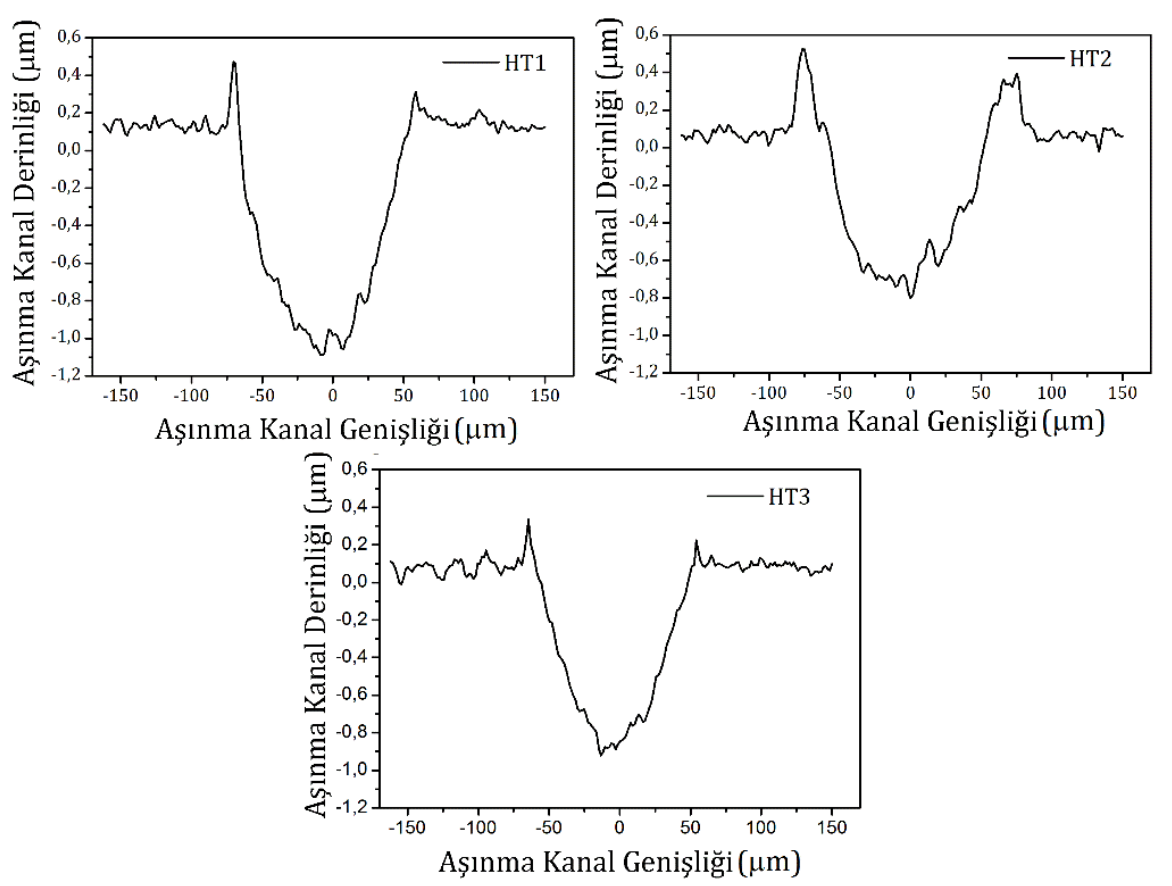

Şekil 9. Numunelere ait aşınma kanal profilleri

Şekil 9'da, aşınma kanallarının profilleri görülmektedir. Aşınma profillerinin alanları üzerinden yapılan aşınma oranı hesaplarına göre HT1, HT2 ve HT3 numunelerine ait aşınma oranları $(\mathrm{mm} 3 / \mathrm{N} / \mathrm{m})$ sirasiyla 1.18E-05, 8.44E06, 7.24E-06'dır. Şekil 9 üzerinde de açıkça görüleceği üzere HT1 numunesi en fazla aşınan, HT3 numunesi ise en az aşınan numune olduğu belirlenmiștir. Mikroyapı analizlerinde de bahsedildiği üzere derin kriyojenik işlem sonrasında yapıda oluşan kararlı karbürler numunelerin aşınma direncinde etkin bir rol oynadığı görülmektedir. Ayrıca XRD analizlerinde de bahsedildiği üzere HT3 numunesinde HT2 numunesine göre kalıntı östenit miktarının fazla olduğu belirlenmiștir. Literatürde de bahsedildiği üzere stabil kalıntı östenitin yağlayıcı etkisi ile bir miktar daha aşınma direncinin artması ile HT3 numunesi en iyi tribolojik özellikleri sergilemiştir.

\section{Tartışma ve Sonuç}

AISI M2 yüksek hız çeliğine 3 farklı ısıl işlem uygulanarak mikroyapısal ve mekanik özellikleri incelenmiștir. Uygulanan derin kriyojenik ișlem neticesinde yapıda ikincil karbür adı verilen ufak yeni karbürler homojen dağılım sergileyerek oluşmaktadır. Farklı ısıl işlemler sonrasında sertlik değerlerinde kriyojenik işlem sonrasında bir miktar artmasına rağmen belirgin bir farklılık tespit edilmemiştir. Sertlik, aşınma davranışını etkileyen bir parametredir. Sertliğin artması ile aşınma dayanımınında beraberinde artması beklenir. Literatürde de 1-2 HRC'lik sertlik değişimleri belirlenmiştir. Buna rağmen kriyojenik işlem sonrasında mikroyapıda meydana gelen karbürlerin, malzemenin aşınma davranışının iyileştirdiğinden bahsedilmektedir. Farklı ısıl işlemler sonrasında bütün numunelerin mikroyapıların da MC, $\mathrm{M}_{6} \mathrm{C}$ karbürlerinin meydana geldiği belirlenmiștir. HT2 ve HT3 numunelerinde ise, kriyojenik işlem uygulanması sonucunda mikroyapılarında 1 $\mu$ m'den de küçük yeni ikincil karbürlerin meydana geldiği belirlenmiștir. Kriyojenik işlemli numunelerin konvansiyonel su verme yöntemine göre daha iyi tribolojik özellikler gösterdiği belirlenmiştir. Konvansiyonel su verme+temper+derin kriyojenik ișlemi (HT3) uygulanmıș numunenin yapısındaki yağlayıcı özellikli kalıntı östenit ve ikincil karbürler sayesinde en düșük sürtünme katsayısı ve așınma oranına sahip olduğu belirlenmiștir. Bu iyileşme sayesinde, özellikle sac metal imalat sektöründe kullanılan zımba takımlarının aşınma dirençlerinin artmasından dolayı, 


\section{DEÜ FMD 22(66), 801-811, 2020}

kullanım ömürlerinin artması ve aynı zamanda düşük sürtünme katsayısından dolayı daha düşük enerji tüketimi ile imalatın gerçekleștirilebilmesi mümkün olacaktır.

\section{Teşekkür}

Bu çalıșma kapsamında uygulanan ısıl ișlemler MMD Ltd.

(www.mmdtekno.com) tarafından gerçekleștirilmiștir.

\section{Kaynakça}

[1] Godec, M., Vecko Pirtovsek, T., Setina Batic, B. McGuiness, P., Burja, L., Podgornik, B. 2015. Surface and Bulk Carbide Transformations in High-Speed Steel. Scientific Reports, Cilt. 5, s. 16202. DOI: 10.1038/srep16202

[2] Gill, S. S., Singh, R., Singh, J., Singh, H. 2012. Adaptive neuro-fuzzy inference system modeling of cryogenically treated AISI M2 HSS turning tool for estimation of flank wear, Expert Systems with Applications, Cilt. 39, s. 4171-4180. DOI: 10.1016/j.eswa.2011.09.117

[3] Öteyaka, M.Ö., Çakır, F.H., Celik, O.N. 2020. Influence of shallow and deep cryogenic treatment on the corrosion behavior of Ti6Al4V alloy in isotonic solution, Materials and Corrosion, s. 1-10. DOI: $10.1002 /$ maco. 201911378

[4] Özer, M. 2019. AISI H13 Takım Celiğine Uygulanan Derin Kriyojenik İșlem ve Temperleme Isıl İșleminin Mikroyapı, Sertlik ve Darbe Enerjisine Etkisi, Gaz Üniversitesi Fen Bilimleri Dergisi Part C: Tasarım ve Teknoloji, Cilt. 7, s. 688-699. DOI: 10.29109 /gujsc. 603355

[5] Ciçek, A., Kıvak, T., Uygur, I, Ekici, E, Turgut, Y. 2011. Performance of cryogenically treated M35 HSS drills in drilling of austenitic stainless steels, The International Journal of Advanced Manufacturing Technology, Cilt. 60, s. 65-73. DOI: $10.1007 / \mathrm{s} 00170$ 011-3616-8

6] Chopra, S. A., Sargade, V.G. 2015. Metallurgy behind the Cryogenic Treatment of Cutting Tools: An Overview, Materials Today: Proceedings, Cilt. 2, s. 1814-1824.

DOI: 10.1016/j.matpr.2015.07.119

[7] Shen, Y. F., Qiu, L.N., Sun, X., Zuo, L., Liaw, P.K., Raabe D. 2015. Effects of retained austenite volume fraction, morphology, and carbon content on strength and ductility of nanostructured TRIPassisted steels, Materials Science and Engineering: A $\begin{array}{llll}\text { Cilt. } & 636 & \text { s. } & 551-564 .\end{array}$ 10.1016/j.msea.2015.04.030

[8] Totten, G. E. 2006. Steel Heat Treatment: Metallurgy and Technologies: Taylor \& Francis. Boca Raton, 848s.

[9] Serna, M.M., Jesus, E.R.B., Galego, E, Martinez, L.G. Corrêa, H.P.S., Rossi, J. L. 2006. An Overview of the Microstructures Present in High-Speed Steel Carbides Crystallography, Materials Science Forum, Cilt. 530-531, s. 48-52. 10.4028/www.scientific.net/MSF.530-531.48

[10] Li, J., Yan, X., Liang, X., Guo, H., Li, D.Y. 2017. Influence of different cryogenic treatments on hightemperature wear behavior of M2 steel, Wear, Cilt
376-377, s. $1112-1121$.

DOI: 10.1016/j.wear.2016.11.041

[11] Oppenkowski, A., Weber, S., Theisen, W. 2010. Evaluation of factors influencing deep cryogenic treatment that affect the properties of tool steels, Journal of Materials Processing Technology, Cilt. 210, s. 1949-1955. 10.1016/j.jmatprotec.2010.07.007

[12] Hossain, R. Pahlevani, F. Sahajwalla V. 2019. Stability of retained austenite in high carbon steel Effect of post-tempering heat treatment, Materials Characterization, Cilt. 149, s. 239-247. DOI: 10.1016/j.matchar.2019.01.034

[13] Das, D., Dutta, A.K., Ray, K.K. 2010. Sub-zero treatments of AISI D2 steel: Part I. Microstructure and hardness, Materials Science and Engineering: A, Cilt. 527, s. 2182-2193. DOI: 10.1016/j.msea.2009.10.070

[14] Pan, F.-s., Wang, W.-q., Tang, A.-t., Wu, L.-z., Liu, T.-t., Cheng, R.-j. 2011. Phase transformation refinement of coarse primary carbides in M2 high speed steel, Progress in Natural Science: Materials International, Cilt. 21, s. 180-186.

[15] Zhou, X.F., Fang, F., Jiang, J.Q., Zhu, W.L., Xu, H.X. 2013. Refining carbide dimensions in AISI M2 high speed steel by increasing solidification rates and spheroidising heat treatment, Materials Science and Technology, Cilt. 30, s. 116-122. DOI: 10.1179/1743284713Y.0000000338

[16] Zhou, B., Shen, Y., Chen, J., Cui, Z.-s. 2011. Breakdown Behavior of Eutectic Carbide in High Speed Steel During Hot Compression, Journal of Iron and Steel Research, International, Cilt. 18, s. 41-48.

[17] Peng, H., Hu, L., Ngai, T., Li, L., Zhang, X., Xie, H., Gong, W. 2018. Effects of austenitizing temperature on microstructure and mechanical property of a 4-GPagrade PM high-speed steel, Materials Science and Engineering: A, Cilt. 719, s. 21-26. DOI: 10.1016/j.msea.2018.02.010

[18] Ghasemi-Nanesa, H., Jahazi, M. 2014. Simultaneous enhancement of strength and ductility in cryogenically treated AISI D2 tool steel, Materials Science and Engineering: A, Cilt. 598, s. 413-419. DOI: 10.1016/j.msea.2014.01.065

[19] Yan, X.G., Li, D.Y. 2013. Effects of the sub-zero treatment condition on microstructure, mechanical behavior and wear resistance of W9Mo3Cr4V high speed steel, Wear, Cilt. 302, s. 854-862. DOI: 10.1016/j.wear.2012.12.037

[20] Versaci, R.A., 1988. Stability of carbides in M2 high speed steel, Journal of Materials Science Letters, Cilt. 7, s. 273-275. DOI: 10.1007/BF01730195

[21] $\mathrm{Li}, \mathrm{H}$, Tong W Cui, J Zhang $\mathrm{H}$, Chen, L, Zuo, L. 2016. The influence of deep cryogenic treatment on the properties of high-vanadium alloy steel, Materials Science and Engineering: A, Cilt. 662, s. 356-362. DOI: 10.1016/j.msea.2016.03.039

[22] Serna, M.M., Rossi, J.L. 2009. MC complex carbide in AISI M2 high-speed steel, Materials Letters, Cilt. 63, s. 691-693. DOI: 10.1016/j.matlet.2008.11.035

[23] Firouzdor, V., Nejati, E., Khomamizadeh, F. 2008. Effect of deep cryogenic treatment on wear resistance and tool life of M2 HSS drill, Journal of Materials Processing Technology, Cilt. 206, s. 467472. DOI: 10.1016/j.jmatprotec.2007.12.072 
DEÜ FMD 22(66), 801-811, 2020

[24] Grairia, A., Beliardouh, N.E., Zahzouh, M., Nouveau, C., Besnard, A. 2018. Dry sliding wear investigation on tungsten carbide particles reinforced iron matrix composites, Materials Research Express, Cilt. 5, s. 116528. DOI: 10.1088/2053-1591/aade07

[25] Das, D., Dutta, A.K., Ray, K. K. 2009. Correlation of microstructure with wear behaviour of deep cryogenically treated AISI D2 steel, Wear, Cilt. 267 s. $1371-1380$.

DOI: 10.1016/j.wear.2008.12.051

[26] Zhang, M., Chen, C., Qin, L., Yan, K., Cheng, G., Jing, H.,

Zou, T. 2017. Laser additive manufacturing of M2

high-speed steel, Materials Science and Technology,

Cilt. 34, s. 69-78.

DOI: $10.1080 / 02670836.2017 .1355584$ 